\title{
Patent Foramen Ovale Closed Before Robotic Radical Prostatectomy
}

\author{
Olivier Pruszkowski, MD, Jérôme Petit, MD, Sylvie Schlumberger, MD, Marc Fischler, MD \\ Department of Anesthesiology, Hôpital Foch and University Versailles Saint-Quentin en Yvelines, 92150 Suresnes, France \\ (Drs. Pruszkowski, Schlumberger, and Fischler). \\ Department of Cardio-Vascular Radiology, Hôpital Marie-Lannelongue, 92350 Le Plessis-Robinson, France (Dr. Petit).
}

\begin{abstract}
Introduction: Robotic prostatectomy is considered by many urologists as the new standard of care.

Cases Description: We encountered 2 patients scheduled for a robotic prostatectomy whose past medical history was remarkable for a cerebral palsy that had been considered to be due to a patent foramen ovale. At this time, it was decided that foramen ovale closure was not necessary. Because of the high risk of gas embolism during the robotic prostatectomy, we decided to close the foramen ovale preoperatively. This procedure and the prostatectomy were without any complication.
\end{abstract}

Conclusions: Our choice of a prophylactic closure of a patent foramen ovale before a procedure at risk of gas embolism is unusual and can be discussed.

Key Words: Foramen Ovale, Laparoscopy, Patent, Prostatectomy, Robotics.

Citation Pruszkowski O, Petit J, Schlumberger S, Fischler M. Patent foramen ovale closed before robotic radical prostatectomy. CRSLS e2014.00323. DOI: 10.4293/CRSLS.2014.00323.

Copyright (C) 2014 SLS This is an open-access article distributed under the terms of the Creative Commons Attribution-Noncommercial-ShareAlike 3.0 Unported license, which permits unrestricted noncommercial use, distribution, and reproduction in any medium, provided the original author and source are credited.

Address correspondence to: Marc Fischler, MD, Department of Anesthesiology, Hôpital Foch, 40 rue Worth, 92151 Suresnes, France. Telephone: 00331-46252433, Fax: 00331-46252088, E-mail: m.fischler @hopital-foch.org

\section{INTRODUCTION}

It is very common for a patient with a patent foramen ovale (PFO) to be scheduled for a surgical procedure with risk of gas embolism. A singular feature is the case of a patient who had suffered from a previous complication related to the PFO such as a cerebral stroke. We encountered 2 such cases and decided to perform a preventive closure of the PFO.

\section{CASE 1 DESCRIPTION}

The first patient was a 50-year-old man scheduled for robotic prostatectomy. He had suffered from a left ischemic rolandic cerebral palsy 6 months previously with no significant sequelae. At that time, transesophageal echocardiography (TEE) had revealed a PFO. As all other investigations were negative, it was considered highly probable that the stroke was due to a paradoxical embolism. Cardiologists had recommended aspirin, but they had decided that closure was not necessary. The question of the relevance of foramen ovale closure was raised again during the anesthetic consultation due to the risk of paradoxical gas embolism. The surgical team considered that it would be a loss of chance to perform a radical prostatectomy via laparotomy. The patient consulted a cardiologist, who specialized in PFO closure, and accepted this procedure after receiving benefit and risk information. Percutaneous closure (Amplatzer device; St. Jude Medical, Plymouth, Minnesota) performed under local anesthesia was uneventful, followed by a 3-month treatment with clopidogrel and aspirin. Robotic prostatectomy was then performed without any adverse effects; notably, there was no sign of gas embolism. Postoperative course was uneventful and the patient was well 6 months after surgery.

\section{CASE 2 DESCRIPTION}

The second patient was a 68-year-old man scheduled also for robotic prostatectomy. He had suffered 6 years earlier from a motor deficit of the right arm with no significant 
sequelae. At that time, transthoracic echocardiography had revealed a PFO with an atrial septal aneurysm. Cardiologists had recommended aspirin and decided that closure was not necessary. As in the previous case, the question of the relevance of closure was raised during the anesthetic consultation, and it was decided to adopt the same strategy. In this case, the delay between the percutaneous PFO closure and the robotic prostatectomy was only 1 month. These procedures were performed without any adverse effect. Postoperative course was uneventful, and the patient was well 6 months after surgery.

\section{DISCUSSION}

Abnormalities in the atrial septum range in severity from PFO to atrial septal defects.

The normal atrial septum consists of 2 layers - the septum primum and the septum secundum. The septum primum forms first, but leaves a window, the ostium secundum. The septum secundum forms later and usually covers the ostium secundum. An atrial septal defect appears if the septum secundum fails to cover the ostium secundum and results in a left-to-right shunt, which causes a volume overload of both the right atrium and the right ventricle. With time, this condition can result in pulmonary hypertension, and reversal of the pressure gradient across the atrial septal defect causes the shunt to reverse as a rightto-left shunt (ie, Eisenmenger syndrome) with cyanosis.

An atrial septal defect is present in 0.70 of 1000 persons while the prevalence of a PFO, evaluated by Hagen et $\mathrm{al}^{1}$ from autopsy specimens of human hearts, is $27.3 \%$ with a progressive decline with increasing age from $34.3 \%$ during the first 3 decades of age to $25.4 \%$ during the 4 th through 8th decades and $20.2 \%$ during the 9th and 10th decades. The origin of a PFO is completely different from that of an atrial septal defect. A portion of the blood from the inferior vena cava passes from the right to the left atrium through the PFO during fetal life, bypassing the lungs. Pulmonary blood flow increases greatly during neonatal circulatory transition, causing increased left atrial pressure. The resulting atrial pressure differences compress the septum primum against the septum secundum, functionally closing the PFO, but this anatomic closure is incomplete in approximately 1 of every 4 adults. Therefore, PFO should be considered a normal anatomic variant and not a pathological finding in the absence of possible paradoxical embolism or other specific clinical conditions. ${ }^{2}$ The physiological implications of a PFO vary depending on interatrial pressure gradient and streaming. Of prime importance is any situation during which right atrial pressure becomes greater than left atrial pressure: pulmonary embolism of any mechanism, Valsalva maneuver, mechanical ventilation with a positive end-expiratory pressure, etc.

To our knowledge, there are only 2 published cases of a closure of a PFO before a scheduled surgical procedure. The first was a young patient who had a post-traumatic fat embolism syndrome. PFO closure was performed before the surgical repair of a femoral fracture. ${ }^{3}$ The second was a 74-year-old woman scheduled for a total hip replacement; she had suffered 2 consecutive cerebellar ischemic strokes that were considered to be paradoxical embolisms. Indeed, TEE revealed an interatrial septum aneurysm with a PFO. ${ }^{4}$ On the other hand, Thoma et $\mathrm{al}^{5}$ described the case of a patient having a large PFO without any related sign scheduled for a cholecystectomy; finally they retained a laparoscopic approach.

Laparoscopic procedures expose a high risk of carbon dioxide embolism. Hong et $\mathrm{al}^{6}$ reported a $17.1 \%(95 \%$ confidence interval of $0.138 \%-0.204 \%$ ) occurrence of carbon dioxide embolism using TEE during laparoscopic radical prostatectomy. Their report confirms this wellknown potential complication of all surgical procedures using carbon dioxide insufflation, with some carrying up to a $100 \%$ risk such as total laparoscopic hysterectomy. ${ }^{7}$ Robotic prostatectomy carries probably the same risk of gas embolism as laparoscopic radical prostatectomy as both procedures use carbon dioxide insufflation.

Massive intravascular irruption of carbon dioxide can cause an acute increase of right ventricular afterload that could lead to low cardiac output or even to death, as in a recently published case. ${ }^{8}$ On the opposite, intravascular bubbles of carbon dioxide are generally considered safe, because of the high solubility of carbon dioxide in the blood (Ostwald solubility coefficient 0.49 ), which is 20 times greater than that of oxygen and it is regularly reported that carbon dioxide bubbles disappear within 20 to 30 seconds. However, this image of short-lived bubbles is incorrect because carbon dioxide is used as an intravascular contrast agent, particularly for patients with renal insufficiency or with high risk of allergic reaction to standard contrast media that require vascular imaging. ${ }^{9}$ Thus, in an extensive review on carbon dioxide angiography, Cho and Hawkins ${ }^{10}$ reported that carbon dioxide bubbles completely dissolve within 2 to 3 minutes when injected into a vessel. These investigators recommend that $3 \mathrm{~min}-$ utes should elapse between injections of carbon dioxide to prevent the localized accumulation of gas bubbles. This time is obviously longer than the circulation time; there- 
fore, carbon dioxide bubbles injected intravenously can reach the right atrium and the aorta, especially when the right to left heart interval time is reduced by a PFO. This explains why a patient can suffer from pulmonary artery hypertension with transient symptomatic hypotension after a carbon dioxide injection. ${ }^{11}$ Accordingly, Cho and Hawkins ${ }^{10}$ stated that carbon dioxide should be used with caution in patients with pulmonary insufficiency or pulmonary hypertension because of the risk of pulmonary arterial pressure and should not be used in patients with an intracardiac septal defect or a pulmonary arteriovenous malformation because of the possibility of paradoxical gas embolism.

Carbon dioxide bubbles that have reached the right heart have several possible issues. They can be filtered by the lungs, ${ }^{12}$ but this filter is limited in case of a large volume of gas. They can create an acute right ventricular outflow obstruction as in the well-described case of a patient who suffered from carbon dioxide embolism during minimally invasive saphenous vein harvesting. ${ }^{13}$ Finally, carbon dioxide bubbles can reach the left heart through a PFO or less frequently through an arteriovenous malformation resulting in intrapulmonary shunting. The complications that follow, particularly cerebral complications, are due to the arteriolar obstruction. Obstruction is mainly due to the transformation of gas bubbles to "solid" bubbles because of platelet adhesion. ${ }^{14}$ Such solid bubbles act like foreign bodies causing ischemia and local inflammatory cascade with a prothrombotic effect. ${ }^{15}$ Otherwise, carbon dioxide induces local toxicity with major local acidosis induced by the gas diffusion, and finally a general inflammatory reaction due to liberation of cytokines from the injured arterial endothelium. ${ }^{16}$

Despite these well-known complications reported in multiple clinical cases, Thoma et $\mathrm{al}^{5}$ chose not to close the PFO of a patient scheduled for a laparoscopic cholecystectomy and known to have this defect. Their principal points were the safety of small intravascular quantities of carbon dioxide because of the high solubility of carbon dioxide with rapid absorption of bubbles ${ }^{17}$ and the reversal of clinical signs of carbon dioxide embolism. Thoma et $\mathrm{al}^{5}$ cited the use of carbon dioxide for angiography to reinforce the low risk of their intravascular injection, but they also wrote that cerebral angiography with carbon dioxide contrast is considered unsafe, with bubble-related vaso-occlusion. ${ }^{18}$ Finally, Thoma et $\mathrm{al}^{5}$ concluded that the benefits of laparoscopic surgery, with better postoperative course after laparoscopic procedures compared with open surgery, greatly exceed the immeasurably small risk of paradoxical emboli. Their consensus plan was to perform the laparoscopic cholecystectomy during general anesthesia using intraoperative TEE monitoring in addition to standard anesthesia monitoring. This plan was explained to the patient, who wanted more time to reflect on the risks, went back home, and had no surgery.

We followed the same steps as Thoma et $\mathrm{al}^{5}$ : analysis of the literature and discussion with the surgical team and a specialized cardiologist. We came to a completely different conclusion: preoperative prophylactic closure of the $\mathrm{PFO}$ and a subsequent laparoscopic procedure. Both procedures were uneventful. Findings of a recent study, ${ }^{19}$ showing that patients with permanent right-to-left shunt have potentially a higher risk of paradoxical embolism compared with those with Valsalva manoeuver-induced right-to-left shunt could perhaps help in such cases.

A problematic issue for anesthesiologists is neurosurgical procedures performed in the sitting position that carry a high risk of air embolism, around one-third of the cases. A Swiss team proposes a systematic preoperative screening for PFO and its closure when the sitting position is the preferred neurosurgical approach. ${ }^{20}$

Among the numerous studies on the technical aspect of the percutaneous PFO closure, one of the most recently reported is the CLOSURE I (Evaluation of the STARFlex Septal Closure System in Patients With a Stroke or TIA due to the Possible Passage of a Clot of Unknown Origin Through a Patent Foramen Ovale [PFO]) study, which evaluated the STARFlex septal closure system (NMT Medical, Inc, W. L. Gore \& Associates, Inc, Flagstaff, Arizona). The rate of effective PFO closure was $86 \%$, and the occurrence of major vascular procedural complications was $3.2 \%{ }^{21}$ Finally, even if the collateral benefit of PFO closure in general is out of our scope, it must be known that percutaneous PFO closure is more effective than medical treatment for the secondary prevention of recurrent cerebrovascular events among patients with PFO-related transient ischemic attack or stroke. ${ }^{22}$

\section{CONCLUSIONS}

Prophylactic closure of a PFO before a procedure at risk of gas embolism is unusual. Some facts are well established: the occurrence of gas embolism is high during laparoscopic procedures; percutaneous closure is a highly successful and very low risk procedure. But the clinical decision in patients with known PFO, a fortiori when they have suffered from a previous paradoxical embolism, is difficult and must involve a fully informed patient. Our cases were patients submitted to robotic radical prostatectomy but similar cases are encountered in patients requiring much more frequent proce- 
dures such as laparoscopic cholecystectomy. The question of medical attitude is even more difficult in these cases. Derouin et $\mathrm{al}^{23}$ have demonstrated using TEE that gas embolism occurs commonly during this procedure. A few major complications, including deaths, have been reported to be the consequence of carbon dioxide embolism. Case reports have a low level of evidence, but their interest is to show that the problem exists.

\section{References:}

1. Hagen PT, Scholz DG, Edwards WD. Incidence and size of patent foramen ovale during the first 10 decades of life: an autopsy study of 965 normal hearts. Mayo Clin Proc. 1984;59(1): $17-20$.

2. Kutty S, Sengupta PP, Khandheria BK. Patent foramen ovale: the known and the to be known. J Am Coll Cardiol. 2012;59(19): 1665-1671.

3. Forteza AM, Rabinstein A, Koch S, et al. Endovascular closure of a patent foramen ovale in the fat embolism syndrome: changes in the embolic patterns as detected by transcranial Doppler. Arch Neurol. 2002;59(3):455-459.

4. Pigot B, Kirkham D, Eyrolles L, Rosencher N, Safran D, Cholley B. Preventive closure of a patent foramen ovale before total hip replacement. BrJ Anaesth. 2009;102(6):888-889.

5. Thoma MS, Maa J, Schiller NB, Litt L. Cholecystectomy in the presence of a large patent foramen ovale: laparoscopic or open? J Clin Anesth. 2010;22(7):553-556.

6. Hong JY, Kim WO, Kil HK. Detection of subclinical CO2 embolism by transesophageal echocardiography during laparoscopic radical prostatectomy. Urology. 2010;75(3):581-584.

7. Kim CS, Kim JY, Kwon JY, et al. Venous air embolism during total laparoscopic hysterectomy: comparison to total abdominal hysterectomy. Anesthesiology. 2009;111(1):50-54.

8. Kim IS, Jung JW, Shin KM. Cardiac arrest associated with carbon dioxide gas embolism during laparoscopic surgery for colorectal cancer and liver metastasis: a case report. Korean J Anesthesiol. 2012;63(5):469-472.

9. Shaw DR, Kessel DO. The current status of the use of carbon dioxide in diagnostic and interventional angiographic procedures. Cardiovasc Intervent Radiol. 2006;29(3):323-331.

10. Cho KJ, Hawkins IF. Carbon dioxide angiography. Medscape Web site. http://emedicine.medscape.com/article/423121overview. Accessed September 27, 2013.
11. Boyd-Kranis R, Sullivan KL, Eschelman DJ, Bonn J, Gardiner GA. Accuracy and safety of carbon dioxide inferior vena cavography. J Vasc Interv Radiol. 1999;10(9):1183-1189.

12. Butler BD, Hills BA. The lung as a filter for microbubbles. J Appl Physiol Respir Environ Exerc Physiol. 1979;47(3):537-543.

13. Martineau A, Arcand G, Couture P, Babin D, Perreault LP, Denault A. Transesophageal echocardiographic diagnosis of carbon dioxide embolism during minimally invasive saphenous vein harvesting and treatment with inhaled epoprostenol. Anesth Analg. 2003;96(4):962-964.

14. Eckmann DM, Armstead SC, Mardini F. Surfactants reduce platelet-bubble and platelet-platelet binding induced by in vitro air embolism. Anesthesiology. 2005;103(6):1204-1210.

15. Muth CM, Shank ES. Gas embolism. N Engl J Med. 2000; 342(7):476-482.

16. Kapoor T, Gutierrez G. Air embolism as a cause of the systemic inflammatory response syndrome: a case report. Crit Care. 2003;7(5):R98-R100.

17. Dion YM, Levesque C, Doillon CJ. Experimental carbon dioxide pulmonary embolization after vena cava laceration under pneumoperitoneum. Surg Endosc. 1995;9(10):1065-1069.

18. Wilson AJ, Boxer MM. Neurotoxicity of angiographic carbon dioxide in the cerebral vasculature. Invest Radiol. 2002;37(10): 542-551.

19. Rigatelli G, Dell'Avvocata F, Cardaioli P, et al. Permanent right-to-left shunt is the key factor in managing patent foramen ovale. J Am Coll Cardiol. 2011;58(21):2257-2261.

20. Fathi AR, Eshtehardi P, Meier B. Patent foramen ovale and neurosurgery in sitting position: a systematic review. $\mathrm{Br} J \mathrm{An}$ aesth. 2009;102(5):588-596.

21. Furlan AJ, Reisman M, Massaro J, et al., for the CLOSURE I Investigators. Closure or medical therapy for cryptogenic stroke with patent foramen ovale. $N$ Engl J Med. 2012;366(11):991-999.

22. Wahl A, Juni P, Mono ML, et al. Long-term propensity scorematched comparison of percutaneous closure of patent foramen ovale with medical treatment after paradoxical embolism. Circulation. 2012;125(6):803-812.

23. Derouin M, Couture P, Boudreault D, Girard D, Gravel D. Detection of gas embolism by transesophageal echocardiography during laparoscopic cholecystectomy. Anesth Analg. 1996; 82(1):119-124. 